\title{
Anatomically corrected malposition of great arteries
}

Sir:

We believe that Anderson et al. in their descriptions and discussions of four cases of anatomically corrected malpositions of the great arteries (British Heart fournal (1975), 37, 993), do not emphasize sufficiently the malpositions of the ventricles and their possible role in the genesis of a wrong aortopulmonary relation and a normal arterioventricular concordance, features that characterize this lesion. All four specimens presented with an anterior left ventricle and posterior right ventricle, except in Case 1 where both ventricles and arteries show sideby-side relation. The cardiac apex was always discordant in regard to the loop (mesocardia and dloop in Case 1, laevocardia and 1-loop in Case 2, dextrocardia and d-loop in Cases 3 and 4). Ventricular malposition has been described in almost all the cases reported with pathological documentation. Based also on our observations (Thiene et al., 1975) we maintain that there is a morphogenetic link between malpositioned ventricles and malpositioned great arteries, and suggest that the ventricular malrotation determines anterior conus emerging from the left ventricle. The conuses are unusually twisted but the wrong torsion seem to be closely related to the malpositioned ventricles. The supposed conal inversion, therefore, does not appear 'isolated'. In other words, anatomically corrected malposition of the great arteries is often a bulboventricular malformation. The fact that the anterior left conus gives origin to the aorta instead of the pulmonary artery depends upon an abnormal truncoconal septation, but this malseptation is secondary to the conal malrotation.

Gaetano Thiene and Vincenzo Gallucci, Istituto di Anatomia Patologica, and Clinica Chirurgica, Università degli Studi, Padova, Italy.

\section{Reference}

Thiene, G., Pellegrino, P. A., Maddalena, F., and Gallucci, V. (1975). Malposizione anatomicamente corretta delle grandi arterie. Giornale Italiano di Cardiologia, 5, 332. We showed this letter to Dr. Anderson and his colleagues who reply as follows:
Sir:

We thank Drs. Thiene and Gallucci for their comments on our paper. Our aim in presenting the cases of anatomically corrected malposition was to emphasize the importance of connexion in diagnosis rather than relations (Shinebourne, Macartney, and Anderson, 1976).

In this aim we could have been more succinct in grouping both 'anatomically corrected malposition' and 'normal relations' together as 'normal connexions'. In this way we could have simplified ventriculo-arterial connexions to four categories, namely, normal connexions (concordant), transposition (discordant), double outlet ventricle, and single arterial trunk. This is as suggested by Kirklin et al. (1973), and we would now agree with them that anatomically corrected malposition is indeed best considered as a concordant connexion. In this way niceties regarding precise relations are avoided. Such niceties have indeed been fostered by one of us (RHA) and we accept that such arguments can be confusing and detract from the main concept (Anderson and Wilkinson, 1975; Quero-Jiménez and Raposo-Sonenfeld, 1975).

The other major point of our article on anatomically corrected malposition was that this concordant ventriculo-arterial connexion could exist with both atrioventricular concordance and discordance. Again, in this situation we emphasize that the connexion is of paramount importance and we are less concerned with ventricular malposition. Thus, in the cases under discussion we specifically did not state the position of the heart within the chest.

We are unable to find in our article any reference to the fact that mesocardia was present in Case 1 and dextrocardia in Case 3. Indeed, we had not observed these facts and do not believe that they can be ascertained from photographs in which the specimens were positioned to show the anatomical features at their best. We would also point out that in Cases 3 and 4 morphological left and right ventricles were not present, as we indicated in our discussion. In Case 3 we believed primitive ventricle without outlet chamber to be present; in 
Case 4 we considered the ventricular morphology to be primitive ventricle with outlet chamber. In this respect it is of interest that both of the cases reported by Thiene et al. (1975) had tricuspid atresia and we would again interpret these specimens as having primitive ventricle with outlet chamber. We would not agree, therefore, that in all the cases the left ventricle is anterior. Furthermore, the precise mode of development of the ventricles is a controversial topic, as is the development of anatomically corrected malposition. It was for this precise reason that we did not emphasize embryogenesis in more detail. We tried to indicate that since these cases were now proven an embryological explanation was desirable. We, therefore, suggested that anatomically corrected malposition could result from conal maldevelopment together with truncal inversion (page 1012).

If we understand the concept of Drs. Thiene and Gallucci correctly we believe this also to be the concept that they are propounding. In this respect, therefore, we are in agreement. However, we would hesitate to associate these events with ventricular malposition.

Robert H. Anderson, Cardiothoracic Institute, Brompton Hospital, London.
Anton E. Becker,

Department of Pathology,

Wilhelmina Gasthuis,

Amsterdam.

Tom G. Losekoot,

Department of Paediatric Cardiology,

Binnen Gasthuis,

Amsterdam.

Leon M. Gerlis,

Department of Pathology, Grimsby General Hospital,

South Humberside.

\section{References}

Anderson, R. H., and Wilkinson, J. L. (1975). Isolated ventricular inversion with situs solitus. British Heart fournal, 37, 1202.

Kirklin, J. W., Pacifico, A. D., Bargeron, L. M., and Soto, B. (1973). Cardiac repair in anatomically corrected malposition of the great arteries. Circulation, 48, 153.

Quero-Jiménez, M., and Raposo-Sonnenfeld, I. (1975). Isolated ventricular inversion with situs solitus. British Heart fournal, 37, 1202.

Shinebourne, E. A., Macartney, F. J., and Anderson, R. H. (1976). Sequential chamber localization - logical approach to diagnosis in congenital heart disease. British Heart fournal, 38, 327.

Thiene, G., Pellegrino, P. A., Maddalena, F., and Gallucci, V. (1975). Malposizione anatomicamente corretta delle grandi arterie. Giornale Italiano di Cardiologia, 5, 332.

\section{A Symposium on Radioisotopes in Cardiology}

Jointly organized by the British Institute of Radiology and the British Cardiac Society this symposium will be held on Wednesday, 29 September 1976, at the Greenwood Conference Centre, Guy's Hospital, London.

A review of the present position will be given by U.K. and overseas speakers. A limited time will be allocated to original presentation for which abstracts in not more than 200 words should be submitted by 30 June.
Registration fee: $£ 9.50$ including lunch, morning coffee, and afternoon tea.

Further details and registration forms will be available from: The Secretary, British Institute of Radiology, 32 Welbeck Street, London W1M 7PG.

Attendance may be limited and registrations will be accepted in the order they are received. 